\title{
Humanização do cuidado à criança em unidade de recuperação pós-anestésica
}

\author{
Humanization of children care in post-anesthetic care units \\ Humanización de la atención al niño en la unidad de recuperación post-anestesia
}

Débora da Silva Anastácio ${ }^{1}$, Maria Izabel Taliberti Pereira de Souza ${ }^{2}$, Lori Anisia Martins de Aquino ${ }^{3}$

RESUMO: Objetivo: Analisar a permanência do familiar junto à criança na Unidade de Recuperação Pós-Anestésica (RPA). Método: Pesquisa quali-quantitativa, descritiva, realizada com 68 sujeitos, entre junho a agosto de 2012, com questões relacionadas à percepção acerca da permanência do familiar junto à criança na unidade de RPA. Resultados: Dos 68 familiares entrevistados, 43 acompanharam suas crianças na RPA. A maioria (40-93\%) ficcou satisfeita em permanecer na unidade de RPA junto de suas crianças. Acalmar a criança e ter a presença da mãe foram os aspectos positivos mais citados pelas acompanhantes. O nervosismo do acompanhante e o incômodo aos profissionais foram os pontos negativos. Conclusão: Os familiares que acompanharam suas crianças ficaram satisfeitos com sua permanência; contudo, referem que ainda falta humanização na assistência. Evidenciou-se que esta prática é uma vontade de todos e que deveria ser adotada em todos os hospitais.

PALAVRAS-CHAVE: Humanização da assistência. Procedimentos cirúrgicos operatórios. Saúde da criança.

ABSTRACT: Objective: To analyze the permanence of the family with the child in Post Anesthetic Care Units (PACU). Method: This is a descriptive, qualitative and quantitative research conducted with 68 subjects between June and August 2012, with issues associated with the perception about the permanence of families with their children in PACUs. Results: Of the 68 families interviewed, 43 accompanied their children in the PACU. The majority (40-93\%) was satisfied to remain in the PACU with their children. Calming the child and having the presence of the mother were the most positive aspects mentioned by caregivers. Nervousness of the companion and nuisance to professionals were the negative aspects. Conclusion: Family members who accompanied their children are satisfied with their stay; however, they mention that the assistance still lacks humanization. It is evident that this practice is a collective will and should be adopted in all hospitals.

KEYWORDS: Humanization of assistance. Surgical procedures, operative. Child health.

RESUMEN: Objetivo: Analizar la permanencia de la familia junto al niño en la Unidad de Recuperación Post Anestésica (URPA). Método: Investigación cualitativa y cuantitativa, descriptiva, realizada con 68 sujetos, entre junio y agosto de 2012, con preguntas relacionadas a la percepción de la permanencia de la familia junto al niño en la URPA. Resultados: De los 68 familiares entrevistados, 43 acompañaron a sus hijos en la URPA. La mayoría (40-93\%) estuvo satisfecha al permanecer con su hijo en la URPA. Calmar al niño y tener la presencia de la madre fueron los aspectos positivos más mencionados por los acompañantes. El nerviosismo del acompañante y la molestia a los profesionales fueron los puntos negativos. Conclusión: Los familiares que acompañaron a sus hijos se quedaron satisfechos con su estancia; sin embargo, afirman que todavía falta humanizar la atención. Se evidenció que esta práctica es una voluntad colectiva de todos y que debería ser adoptada en todos los hospitales.

PALABRAS ClAVE: Humanización de la atención. Procedimientos quirúrgicos operatórios. Salud del niño.

${ }^{1}$ Enfermeira. Bacharel e Licenciada em Enfermagem. Universidade Federal de Uberlândia (UFU).

Av. Equador, 203. Presidente Roosevelt. Uberlândia, MG, Brasil.

Telefones: (34) 3215-4360 / (34) 8826-8723. E-mail: deboranastacio@hotmail.com

${ }^{2}$ Enfermeira. Mestre em Enfermagem Fundamental. EERP-USP. Docente do Curso de Graduação em Enfermagem. Faculdade de Medicina. Universidade Federal de Uberlândia

(UFU). E-mail: beltaliberti@hotmail.com

${ }^{3}$ Enfermeira. Mestre em Educação Superior. Docente do Curso de Graduação em Enfermagem. Faculdade de Medicina. Universidade Federal de Uberlândia (UFU).

E-mail: lorianisia@yahoo.com.br 


\section{Introdução}

A hospitalização é uma vivência que traz angústia e estresse, principalmente quando o paciente/cliente é uma criança, pois a afasta do convívio e do ambiente familiar no qual estava inserida, provocando sofrimento e podendo surgir problemas emocionais e comportamentais. Em se tratando de Centro Cirúrgico (CC), os sentimentos de medo e ansiedade tendem a aumentar, pois a mesma se depara com um espaço diferente, fechado, com acesso restrito, pessoas estranhas e uso de uniforme privativo, dificultando a comunicação e a relação da Equipe de Enfermagem com a criança e seus familiares; consequentemente, tal situação acaba impedindo um atendimento de qualidade e humanitário.

A literatura a respeito da hospitalização infantil indica que esta vem caminhando em direção à humanização e passando por transformações. Até a década de 1980, os textos exploravam os efeitos da hospitalização na saúde física e mental da criança. Após esse período, enfatizam os benefícios da participação do responsável ou familiar como acompanhante e os conflitos surgidos entre estes e a Equipe de Enfermagem, assim como a tentativa de evitar esses conflitos ${ }^{1}$.

A assistência de Enfermagem ao cliente pediátrico cirúrgico deve ser prestada nos períodos pré, trans e pósoperatórios de forma individualizada; contudo, para que a mesma seja realizada com eficiência e qualidade, é preciso também atender às necessidades do familiar, para que assim haja um atendimento integral, digno e humanitário.

No período pós-operatório imediato, o paciente é encaminhado à unidade de Recuperação Pós-anestésica (RPA), na qual deverá permanecer até estar consciente, livre dos efeitos anestésicos e com os sinais vitais estáveis. Neste período, a criança poderá estar agitada, chorosa, confusa, sonolenta, entre outras características que provocam estresse, ansiedade, angústia. Estando ao lado de seus pais, as crianças ficam mais seguras, gerando tranquilidade para a família. Além disso, o familiar estará atento às alterações no estado de sua criança, podendo manter uma parceria com a Equipe de Enfermagem e vice-versa ${ }^{2}$.

O Programa Nacional de Humanização da Assistência Hospitalar (PNHAH) ${ }^{3}$, criado pelo Ministério da Saúde em 2001, propõe um conjunto de ações integradas que visam a mudar substancialmente o padrão de assistência ao usuário nos hospitais públicos do Brasil, melhorando a qualidade e a eficácia dos serviços hoje prestados por estas instituições. $\mathrm{O}$ objetivo principal do PNHAH é aprimorar as relações entre profissionais de saúde e clientes, dos profissionais entre si e do hospital com a comunidade.

Assim, a humanização da assistência à criança e seu familiar é de fundamental importância, a fim de transmitirlhes segurança e integridade emocional, num momento tão crítico do tratamento, como a cirurgia ${ }^{4}$.

Horta ${ }^{5}$, em sua Teoria das Necessidades Humanas Básicas, refere que, dentre as necessidades mais afetadas, estão a segurança emocional e física. Para o cliente pediátrico cirúrgico, a segurança emocional alterada implica em manifestações de tensão, ansiedade e stress, que podem ser expressas por choro, atividade motora exagerada, mudez, pouca interação interpessoal e tristeza. Já a segurança física prejudicada envolve acidentes, como cair da maca, acessos venosos arrancados bruscamente pela criança, lesões com objetos pérfuro-cortantes durante procedimento devido à agitação extrema da mesma, entre outros.

Baseado na legislação 8.069 de 13 de julho de 1990, que dispõe sobre o Estatuto da Criança e do Adolescente ${ }^{6}$, no tocante ao Direito à Vida e à Saúde, o Artigo 12 refere que "os estabelecimentos de atendimento à saúde deverão proporcionar condições para a permanência em tempo integral de um dos pais ou responsável, nos casos de internação de criança ou adolescente".

Considera-se essencial a presença do familiar junto à criança, possuindo, mesmo, algumas funções sociais, como relação de intimidade, afeto e solidariedade, que representam ainda um sistema de cuidado, fornecendo suporte nas diversas situações. O Enfermeiro, ao se envolver com o familiar, tem a percepção de todo o contexto no qual cada um está inserido, desenvolvendo, a partir daí, o processo de interação ${ }^{4}$.

Neste estudo, partimos do pressuposto de que há necessidade da permanência do familiar junto à criança, na recuperação pós-anestésica.

\section{Objetivos}

- Verificar a opinião dos familiares quanto à sua permanência na unidade de RPA;

- Identificar, sob a ótica dos familiares, os aspectos positivos e negativos da sua presença.

\section{Método}

Trata-se de uma pesquisa quali-quantitativa, descritiva, realizada com 68 sujeitos no período de junho a agosto de 2012. Foi utilizada a entrevista estruturada, com questões relacionadas à caracterização do acompanhante e à sua percepção acerca da permanência do familiar junto à criança na unidade de RPA.

Para desenvolver uma pesquisa qualitativa, é necessário, como afirma $\mathrm{Minayo}^{7}$, a realização de um trabalho de campo. O campo de pesquisa se constituiu das Unidades de Internação Pediátrica (Enfermaria de Pediatria, Unidade de Terapia Intensiva Pediátrica e Pronto Socorro - PS Pediatria) do Hospital de Clínicas de Uberlândia, da Universidade Federal de Uberlândia (HC-UFU).

Os familiares foram selecionados de acordo com a escala de cirurgias pediátricas eletivas do hospital citado e, de posse da mesma, a pesquisadora realizou as entrevistas junto ao leito de internação da criança, no período pós-operatório imediato. 
Foram incluídos nesta pesquisa os familiares ou responsáveis legais pelas crianças até 12 anos de idade, submetidas a cirurgias eletivas no Hospital de Clínicas de Uberlândia, que concordaram em participar do projeto e assinaram o Termo de Consentimento Livre e Esclarecido. Foram excluídos os familiares das crianças submetidas à cirurgia de emergência e os que não concordaram em participar da pesquisa.

De acordo com a Resolução $\mathrm{N}^{\circ}$ 466, de 12 de dezembro de 2012, do Conselho Nacional de Saúde (CNS) ${ }^{8}$, o projeto foi aprovado pelo Comitê de Ética em Pesquisa da Universidade Federal de Uberlândia (CEP-UFU), via Plataforma Brasil, com o CAAE: 00750112.9.0000.5152.

\section{Resultados}

A população estudada constou de 68 familiares ou responsáveis legais de crianças submetidas a cirurgias eletivas no Hospital de Clínicas de Uberlândia, no período de junho a agosto de 2012. Verificou-se que todos os familiares entrevistados eram do sexo feminino, ou seja, 100\% da amostra.

No que se refere ao grau de parentesco da acompanhante, constatamos que 63 (93\%) das mulheres entrevistadas eram as mães das crianças submetidas à cirurgia e que cinco (7\%) eram avós, reforçando o papel fundamental da mulher no cuidado com a criança.

Em relação à faixa etária da população entrevistada, as idades variaram de 19 a 60 anos, com uma média de 32 anos. Verificou-se que a grande maioria, ou seja, 37 (55\%) entrevistadas, estava na faixa etária de 19 a 32 anos, e que a minoria, um número de apenas duas ( $3 \%$ ) entrevistadas, estava entre 47 e 60 anos; 24 (35\%) familiares encontravamse entre 33 e 46 anos e 5 (7\%) responsáveis não responderam acerca de suas idades.

Em relação à pergunta se o familiar acompanhou ou não sua criança na RPA, verificamos que 43 (63\%) entrevistadas acompanharam as crianças naquele setor, enquanto 25 (37\%) não o fizeram.

Destas 25 mulheres que não acompanharam suas crianças na RPA, 12 (48\%) delas não o fizeram devido ao fato de as crianças serem encaminhadas do Centro Cirúrgico diretamente para a UTI Pediátrica.

Já as outras 13 (52\%) entrevistadas que não acompanharam suas crianças na RPA não o fizeram por falta de informação de que poderiam estar juntas de suas crianças na RPA.

No que tange ao desejo de permanecerem na RPA com suas crianças, as 25 entrevistadas, ou seja, 100\% daquelas que não estiveram naquele recinto com as crianças, afirmaram que gostariam de ter acompanhado.

Em relação à avaliação da permanência do familiar na RPA, a maioria, ou seja, 40 (93\%) entrevistadas ficaram satisfeitas com sua permanência na unidade de RPA junto de suas crianças, enquanto que apenas uma (2\%) mãe ficou insatisfeita e duas (5\%) definiram esta permanência como assustadora. Nenhuma das pessoas entrevistadas definiu esta experiência como indiferente.

Quanto à interação do acompanhante com a Equipe de Enfermagem, constatamos que a maioria, ou seja, 41 (96\%) mulheres referiram uma boa interação com a equipe, ao mesmo tempo em que, uma ( $2 \%$ ) relatou essa interação como ruim e uma ( $2 \%$ ) pesquisada caracterizou como indiferente.

De acordo com os dados encontrados, a maioria, ou seja, 96\% dos acompanhantes tiveram uma boa interação com a Equipe de Enfermagem.

Outros aspectos por nós pesquisados foram os pontos positivos e os negativos da permanência do familiar junto de suas crianças na RPA. No que se refere aos pontos positivos, com relação à permanência das mesmas na unidade de RPA, obtivemos o exposto na Tabela 1.

\section{Discussão}

$\mathrm{O}$ fato de prevalecer o sexo feminino como acompanhante reforça a tese de que a mulher é sempre a principal cuidadora. Este dado vai ao encontro com a afirmação de Varella", referindo-se ao fato de ser raro um cuidador do sexo masculino.

Neste sentido, Floriani ${ }^{10}$ afirma que o cuidador se origina na família, sendo a mulher, adulta e idosa, que se sobressai nesse cuidado.

Atualmente, há um aumento considerável de casos em que os avós passam a desempenhar o papel dos pais e, em determinados casos, com todas as funções pertinentes, deixando de viver a experiência de serem simplesmente avós ${ }^{11}$.

Os avós tiveram seus papéis expandidos e aqueles que ora têm netos vivendo consigo, conseguem sua custódia legal e lhes dão cuidados diários, além de se responsabilizarem também financeiramente por eles ${ }^{12}$.

Tabela 1. Depoimento das acompanhantes para definir sua permanência como positiva na unidade de RPA, Uberlândia, 2012.

\begin{tabular}{lcc}
\hline $\begin{array}{c}\text { Pontos positivos da permanência da } \\
\text { acompanhante para a criança }\end{array}$ & $\begin{array}{c}\text { Frequência* } \\
(\mathrm{n}=43)\end{array}$ & \%** \\
\hline Acalmar a criança & 20 & 46,5 \\
Ter a presença da mãe & 9 & 20,9 \\
Dar segurança à criança & 8 & 18,6 \\
Acalmar a acompanhante & 5 & 11,6 \\
Ver a criança & 3 & 6,9 \\
Poder cuidar & 2 & 4,6 \\
Ver o cuidado prestado & 2 & 4,6 \\
Não provocar trauma na criança & 1 & 2,3 \\
\hline
\end{tabular}

*Refere-se ao número de vezes em que a resposta foi citada pelas acompanhantes; **A percentagem foi calculada com base no total de respostas possíveis, ou seja, 43 sujeitos; ressalta-se que foi permitido a cada mãe apontar mais de um ponto positivo; Fonte: Elaborada pelos autores. 
Em estudo realizado sobre as necessidades do acompanhante da criança em unidade de recuperação anestésica, encontraram-se cuidadoras entre 19 e 47 anos, com uma média de 33 anos, do que concluíram que, para cuidar, não tem idade ${ }^{13}$.

Outro estudo, realizado na Turquia, avaliou 40 cuidadores primários de crianças com paralisia cerebral, encontrando 36 mães, dois pais e duas avós, com média de idade de 35 anos; 40 cuidadores primários de crianças sem paralisia cerebral, sendo 35 mães, dois pais e três avós, com média de idade de 34 anos. Esse estudo vai ao encontro dos nossos resultados, evidenciando que as médias de idades de cuidadores de crianças seguem padrão semelhante e que, como descrito anteriormente, na maioria dos estudos, a mãe prevalece como principal cuidadora ${ }^{14}$.

No hospital em estudo, as crianças encaminhadas para a UTI Pediátrica logo após a cirurgia não permanecem em observação na unidade de RPA, sendo o atendimento do período pós-operatório imediato feito na própria UTI.

Possari ${ }^{15}$, analisando a assistência de Enfermagem na RPA, afirma que, no caso de cirurgias de alta complexidade, a recuperação pode ser diretamente na UTI. Esta afirmação vai ao encontro com o que ocorre no hospital em estudo.

Lourenço, Peniche e $\operatorname{Costa}^{16}$, em seu estudo sobre os aspectos organizacionais e assistenciais da RPA em hospitais brasileiros, encontraram que, em $60,9 \%$ das instituições pesquisadas, a presença do acompanhante na RPA é permitida em situações específicas. Contudo, em 34,8\% destas, a presença de acompanhante é proibida em qualquer circunstância, o que torna o hospital passível de pena.

Segundo as Práticas Recomendadas pela Associação Brasileira de Enfermeiros de Centro Cirúrgico, Recuperação Pós-Anestésica e Centro de Material e Esterilização (SOBECC) $)^{17}$, afirma-se que os pais podem e devem permanecer ao lado da criança na RPA, tranquilizando-a durante o período pós-operatório imediato.

No Centro Cirúrgico do hospital em estudo, de acordo com informações colhidas no próprio setor, a permissão de entrada do acompanhante na unidade de RPA foi um processo que ocorreu gradativamente e que começou a ser adotado a partir de 2011, visto que o acompanhamento das crianças reflete em benefícios tanto para as mesmas quanto para os pais.

Em relação às declarações das mães que avaliaram a permanência como satisfatória, citamos alguns depoimentos:

Quando eu cheguei notei que ele estava chorando e nervoso, depois que ele me viu ficou mais calmo e dormiu. (E8)

Não tem nem como explicar, adorei ficar ao lado de minha filha. (E67)

Porque passou tranquilidade tanto para ele quanto para mim. (E53)

Fiquei mais calma, mais segura, meu filho veio embrulhadinho e com o bico dele. (E39)
Gostei de ver que a cirurgia ocorreu com muito sucesso, que a primeira fala de minha filha foi: como estou respirando bem. (E9)

Estes relatos evidenciam a necessidade e a importância da permanência do familiar na unidade de RPA. Carvalho, Paula e Moraes ${ }^{18}$ descrevem que atender às expectativas de pacientes e familiares pode ser representado pelo favorecimento e pela manutenção dos laços afetivos e de segurança, por meio de ações, como incentivar o familiar a acompanhar o cliente até a entrada do centro cirúrgico e, posteriormente, permitir sua presença junto dele na sala de RPA. As autoras afirmam ainda que esta prática tem sido muito benéfica para a criança e para a equipe que a atende.

No que se refere aos depoimentos das acompanhantes que acharam a experiência assustadora, transcrevemos algumas de suas falas:

Minha filha vomitou sangue e eu não sabia, fiquei muito assustada. (E38)

Não estava preparada para presenciar a reação do meu filho. (E56)

Neste sentido, em estudo que relata o significado da permanência dos pais ou acompanhantes na RPA, na percepção de Auxiliares de Enfermagem, destaca-se que foram referidas como dificuldades enfrentadas por esses profissionais as situações em que os pais passam mal ou aqueles que ficam nervosos durante o acompanhamento dos filhos, ressaltando a necessidade de interação da equipe com a família, a fim de detectar suas ansiedades².

Em relação à justificativa da mãe que achou a permanência insatisfatória, obtivemos este depoimento:

Gostaria que fosse separado os adultos das crianças por conta das doenças, lotações de pessoas, falta de conforto e lugar para a mãe ficar. (E1)

Reforçando este achado, também Schmidt, Orasmo e Gil², em seu estudo com Auxiliares de Enfermagem, comentam que os profissionais referiram que a área física pequena dificulta o trabalho, uma vez que não há espaço para pais e profissionais, principalmente nos horários de pico.

Desta forma, dentre os elementos que devem compor a unidade de RPA, deve existir uma área para visitas destinadas à permanência dos familiares e amigos, enquanto aguardam o término da operação ${ }^{15}$.

Por sua vez, Malagutti ${ }^{19}$ afirma que é função do Enfermeiro de Centro Cirúrgico proporcionar estrutura física, recursos humanos e materiais para que o ato anestésico-cirúrgico seja realizado em condições ideais, visando à assistência integral, ao ensino e à pesquisa. Contudo, a necessidade de um espaço específico para os acompanhantes dentro da unidade de RPA não foi encontrada na literatura pesquisada.

O momento de interação com os pais dentro do Centro Cirúrgico é de extrema importância para os componentes da Enfermagem e da Equipe Médica, pois é uma oportunidade de orientá-los quanto aos cuidados e quanto à cirurgia ${ }^{2}$. 
Em relação à boa interação dos acompanhantes com a Equipe de Enfermagem, este fato foi evidenciado através do relato de algumas mães que, ao responderem o questionário da pesquisa, indagaram o porquê de não haver a opção 'ótima' no formulário, pois gostaram muito da Equipe de Enfermagem e da forma como elas e os filhos foram tratados.

A Equipe de Enfermagem representa o elo mais forte entre o cliente e o ambiente onde este se encontra, por serem esses profissionais aqueles que, por maior tempo, exercem atividades junto ao mesmo ${ }^{19}$.

Em se tratando da humanização na RPA, todo paciente submetido a um ato anestésico cirúrgico sofre traumas, tantos psicológicos quanto físicos, pois as incertezas, as dúvidas e os sentimentos em relação ao pós-operatório são intensos ${ }^{20}$. Essa afirmação está de acordo com a preocupação de uma das mães em relação ao fato de não provocar trauma na criança.

As crianças se recuperam mais rapidamente na presença da mãe, uma vez que se sentem seguras, protegidas integralmente, além de as mães serem facilitadoras do cuidado de Enfermagem ${ }^{2}$.

Em relação aos pontos negativos, a maioria, ou seja, 32 (74\%) acompanhantes disseram que não os houve, enquanto que uma mãe $(1 \%)$ relata o nervosismo e outra $(1 \%)$, o incômodo aos profissionais. Neste sentido percebemos que nove $(21 \%)$ das entrevistadas tiveram dificuldades no entendimento da questão, pois responderam relacionando os pontos negativos da unidade e não de sua permanência. Dentre os pontos negativos da unidade, foram os aspectos mais citados: "muitas pessoas em um só local"; "não ter separação de crianças e adultos"; "falta de conforto", e "demora em liberação para retorno às enfermarias".

Com isso, interpreta-se que, na sua maioria, estes responsáveis entendem que sua presença é importante para uma boa recuperação da criança, não observando questões desfavoráveis na sua permanência.

\section{Conclusão}

A hospitalização e a cirurgia representam grande impacto para a criança, que, afastada de seus familiares, sofre medo e angústia; além disso, é submetida a procedimentos dolorosos e passa por grande alteração na sua rotina. Assim como a criança, seus familiares também sofrem por esta separação e pela angústia da incerteza.

De uma forma geral, a maioria das entrevistadas sentiu-se satisfeita com sua permanência na RPA; contudo, percebeuse que não receberam informações dos profissionais em relação ao que elas poderiam encontrar neste ambiente e sobre o estado em que a criança se encontraria. Neste sentido, concluímos que a falta de informação às acompanhantes é um fator que vai contra a humanização da assistência.

Em relação aos pontos positivos da permanência do familiar na RPA, verificamos que, na percepção dos acompanhantes, acalmar a criança e ter a presença da mãe foram os aspectos considerados mais relevantes, seguidos da importância de dar segurança à criança. Já em relação aos pontos negativos, a maioria não os mencionou, porém o nervosismo da acompanhante e o incômodo aos profissionais foram citados por duas entrevistadas.

Finalizando, esperamos que, com este estudo, possamos contribuir para uma assistência mais humanizada à criança operada e ao seu familiar, e concluímos que a permanência do familiar na RPA é uma vontade de todos e que deveria ser adotada em todos os hospitais.

\section{Referências}

1. Pinto JP, Ribeiro CA, Silva CV. Procurando manter o equilíbrio para atender suas demandas e cuidar da criança hospitalizada: a experiência da família. Rev Latino-Am Enferm. 2005;13(6):974981. http://dx.doi.org/10.1590/S0104-11692005000600009.

2. Schmidt DRC, Orasmo CVN, Gil RF. Humanização da criança operada: integração familiar ao ambiente cirúrgico. Rev SOBECC. 2005;10(3):14-22.

3. Brasil. Ministério da Saúde. Secretaria de Assistência à Saúde. Programa Nacional de Humanização da Assistência Hospitalar. Brasília: Ministério da Saúde; 2001.

4. Silva DC, Meirelles NF. Humanização da assistência à criança em centro cirúrgico oncológico. Rev SOBECC. 2009;14(1):30-41.

5. Horta WA. Processo de enfermagem. São Paulo: EPU,EDUSP; 1979. $99 \mathrm{p}$.

6. Brasil. Ministério da Saúde. Lei n ${ }^{8} .069$, de 13 de julho de 1990. Dispõe sobre o Estatuto da Criança e do Adolescente e dá outras providências [Internet]. Brasília: Ministério da Saúde; 1990 [citado 2014 fev. 13]. Disponível em: http://bvsms.saude.gov.br/bvs/ publicacoes/lei_8069_06_0117_M.pdf.

7. Minayo MCS. O desafio do conhecimento:pesquisa qualitativa em saúde. 12. ed. São Paulo: Hucitec; 2010. 408 p.

8. Conselho Nacional de Saúde. Resolução n ${ }^{\circ} 66$, de 12 de dezembro de 2012. Aprova as diretrizes e normas regulamentadoras de pesquisa envolvendo seres humanos. Diário Oficial da República Federativa do Brasil; Brasília; 13 jun. 2013.

9. Varella D. Por um fio. São Paulo: Companhia das Letras; 2004. $222 \mathrm{p}$.

10. Floriani CA. Cuidador familiar: sobrecarga e proteção. Rev Bras Cancerol. 2004;50(4):341-345.

11. Lopes ESL, Neri AL, Park MB. Ser avós ou ser pais: os papéis dos avós na sociedade contemporânea. Textos Envelhecimento [Internet]. 2005 [citado 2014 fev. 13];8(2):239-53. Disponível em: http://revista.unati.uerj.br/scielo.php?script $=$ sci arttext\&pid $=$ S1517-59282005000200006\&lng $=$ es\&nrm $=i$ so.

12. Dellmann-Jenkins M, Blanemeyer M, Olesh M. Adults in expander grandparents roles: considerations for practice, policy, and research. Educ Gerontol. 2002;28(3):219-235. http://dx.doi. org/10.1080/036012702753542526.

13. Jukemura MFM, Peniche ACG. Necessidades do acompanhante da criança em unidade de recuperação anestésica. Rev SOBECC. 2010;15(3):25-32.

14. Tuna H, Unalan H, Tuna F, Kokino S. Quality of life of primary caregivers of children with cerebral palsy: a controlled study with Short Form-36 questionnaire. Dev Med Child 
Neurol. 2004 September;46(9):647-648. http://dx.doi. org/10.1111/j.1469-8749.2004.tb01031.x. PMid:15344526

15. Possari JF. Assistência de enfermagem na recuperação pósanestésica. São Paulo: Iátria; 2003. 142 p.

16. Lourenço MB, Peniche ACG, Costa ALS. Unidades de recuperação pós-anestésica de hospitais brasileiros: aspectos organizacionais e assistenciais. Rev SOBECC. 2013;18(2):25-32.

17. Associação Brasileira de Enfermeiros de Centro Cirúrgico, Recuperação Pós-Anestésica e Centro de Material e Esterilização - SOBECC. Práticas recomendadas SOBECC. 6. ed. rev. São Paulo: SOBECC; 2013.
18. Carvalho R, Paula MFC, Moraes MW. Tecnologia e humanização em centro cirúrgico. In: Carvalho R, Bianchi ERF, organizadoras. Enfermagem em centro cirúrgico e recuperação. São Paulo: Manole; 2007. p. 316-34.

19. Malagutti W. Aspectos estruturais, humanos e materiais. In: Bonfim IM, Malagutti W, organizadores. Recuperação pós-anestésica: assistência especializada no centro cirúrgico. São Paulo: Martinari; 2010. p. 29-39.

20. Bonfim IM. Assistência de enfermagem na RPA. In: Bonfim IM, Malagutti W, organizadores. Recuperação pós-anestésica: assistência especializada no centro cirúrgico. São Paulo: Martinari; 2010. p. 67-79. 